\title{
SIGNIFICADOS DAS EXPERIÊNCIAS CORPORAIS DE PESSOAS COM TUBERCULOSE PULMONAR: A CONSTRUÇÃO DE UMA NOVA IDENTIDADE ${ }^{1}$
}

\author{
Bianca Contreira de Jung², Juliana Graciela Vestena Zillmer³, Fátima Teresinha Scarparo Cunha \\ Roxana Isabel Cardozo Gonzales ${ }^{5}$
}

\footnotetext{
${ }^{1}$ Artigo extraído da dissertação - Os significados da experiência do adoecimento de pessoas com tuberculose, apresentada ao Programa de Pós-Graduação em Enfermagem da Universidade Federal de Pelotas (UFPel), em 2015.

${ }^{2}$ Mestre em Ciências. Professora substituta do Curso de Enfermagem, Departamento de Enfermagem, Fundação Universitária do Rio Grande. Rio Grande, Rio Grande do Sul, Brasil. E-mail: biancajung@furg.com

${ }^{3}$ Doutora em Enfermagem. Professora do Curso de Enfermagem do Departamento de Enfermagem da UFPel. Pelotas, Rio Grande do Sul, Brasil. E-mail: juzillmer@gmail.com

${ }^{4}$ Doutorado em Saúde Coletiva. Professora da Universidade Federal do Estado do Rio de Janeiro. Rio de Janeiro, Rio de Janeiro, Brasil. E-mail: fatima.scarparo@gmail.com

${ }^{5}$ Doutora em Enfermagem em Saúde Pública. Professora da Faculdade de Enfermagem, da UFPel. Pelotas, Rio Grande do Sul, Brasil. E-mail: roxana_cardozo@hotmail.com
}

\section{RESUMO}

Objetivo: compreender os significados das experiências corporais de pessoas em tratamento para tuberculose pulmonar.

Método: pesquisa qualitativa, realizada no município de Pelotas, Estado do Rio Grande do Sul, Brasil. Utilizou-se o referencial teórico da Antropologia em Saúde de Byron Good. Foram realizadas entrevistas semiestruturadas com dez pessoas na segunda fase de tratamento para a tuberculose, em seus domicílios, entre abril e maio de 2015. Para a análise dos dados empregou-se a técnica de Análise de Conteúdo Temática.

Resultados: apreenderam-se duas categorias: O corpo sinalizador da doença que se revela na presença de sintomas (febre, emagrecimento, fraqueza) e O corpo doente que manifesta sofrimento, temor, estigma e afastamento.

Conclusão: a presença da tuberculose no corpo é capaz de gerar apreensão, rompimento das atividades de lazer e trabalho, afastamento do convívio familiar e social. É essencial desenvolver um olhar para o cuidado, compreender as necessidades singulares de quem vive o adoecimento, valorizar a sua história de vida e a sua subjetividade.

DESCRITORES: Tuberculose pulmonar. Acontecimentos que mudam a vida. Corpo. Estigma. Pacientes.

\section{MEANINGS OF THE CORPOREAL EXPERIENCES OF PEOPLE WITH PULMONARY TUBERCULOSIS: THE CONSTRUCTION OF A NEW IDENTITY}

\begin{abstract}
Objective: to understand the meanings of the corporeal experiences of people being treated for pulmonary tuberculosis.

Method: qualitative research, carried out in the municipality of Pelotas, Rio Grande do Sul, Brazil. The theoretical reference of Anthropology in Health by Byron Good was used. Semi-structured interviews were conducted with ten people in the second phase of the treatment for tuberculosis, in their residences, between April and May 2015. For the analysis of the data, the Thematic Content Analysis technique was used. Results: two categories have emerged: The body signaling the disease that reveals itself in the presence of symptoms (fever, weight loss, weakness) and The sick body that manifests suffering, fear, stigma and distancing.

Conclusion: the presence of tuberculosis in the body is capable of generating apprehension, disruption of leisure and work activities, and distancing from family and social life. It is essential to develop a look at care, to understand the unique needs of those who experience the illness, to value their life history and their subjectivity.
\end{abstract}

DESCRITPTORS: Pulmonary Tuberculosis. Life-changing events. Body. Stigma. Patients. 


\section{SIGNIFICADOS DE LAS EXPERIENCIAS CORPORALES DE PERSONAS CON TUBERCULOSIS PULMONAR: LA CONSTRUCCIÓN DE UNA NUEVA IDENTIDAD}

\section{RESUMEN}

Objetivo: comprender los significados de las experiencias corporales de personas en tratamiento por tuberculosis pulmonar.

Método: investigación cualitativa realizada en el municipio de Pelotas, Estado do Rio Grande do Sul, en Brasil. Se utilizó el referente teórico de la Antropología en Salud de Byron Good. Se llevaron a cabo entrevistas semiestructuradas con diez personas en la segunda fase del tratamiento para la tuberculosis, en sus domicilios, entre Abril y Mayo del 2015. Para el análisis de los datos se usó la técnica de Análisis del Contenido Temático.

Resultados: dos categorías surgieron: El cuerpo señalador de la enfermedad que se revela a través de la presencia de síntomas (fiebre, pérdida de peso, debilidad) y El cuerpo enfermo que manifiesta sufrimiento, temor, estigma y alejamiento.

Conclusión: la presencia de la tuberculosis en el cuerpo es capaz de generar aprehensión, finalizar las actividades de placer y trabajo, alejamiento del convivio familiar y social. Es esencial desarrollar una conciencia para el cuidado, comprender las necesidades singulares de quién padece esta enfermedad, valorizar su historia de vida y su subjetividad.

DESCRIPTORES: Tuberculosis pulmonar. Acontecimientos que mudan la vida. Cuerpo. Estigma. Pacientes.

\section{INTRODUÇÃO}

A permanência da tuberculose como um problema emergencial de saúde pública nos países em desenvolvimento, com destaque para o Brasil, faz dela uma doença temida pelo seu risco de contágio e pelo forte estigma que gera sofrimento na família, além do seu risco de adoecer na coletividade e do seu ônus para o sistema de saúde. ${ }^{1}$ A problemática da tuberculose se caracteriza por ser uma enfermidade que deveria estar sob controle, no entanto, sua vinculação às precárias condições sociais torna difícil a resolução desse agravo à saúde. ${ }^{2}$

A fim de obter avanços no controle da doença faz-se necessário o compromisso da sociedade e de seus governos, pautados em uma atuação conjunta, buscando erradicar a miséria, a fome e as condições precárias de habitação das populações carentes. ${ }^{3}$ De certa forma, é essencial considerar a dimensão individual e subjetiva para a compreensão do adoecimento e suas implicações na vida das pessoas, nas famílias, nos serviços de saúde e na sociedade. Políticas e ações de saúde pautadas nessa perspectiva impactam potencialmente na detecção e cura da doença. ${ }^{2}$

Neste sentido, são relevantes estudos que possibilitam conhecer, compreender e interpretar os significados da experiência individual no adoecimento por tuberculose. Deste modo, a partir das experiências da pessoa emergem-se os significados do corpo doente, frutos de uma realidade subjetiva para quem vive com a enfermidade.

Estudo referente à experiência de adoecimento busca compreender as dimensões subjetivas, sociais e culturais da doença como fatores importantes para o reconhecimento do complexo fenômeno da experiência. ${ }^{4}$
O adoecimento é imbuído de significados que são sempre presentes para quem o vive, porém, os modos como as pessoas tecem e atribuem estes significados têm relação direta com a identidade individual e social. ${ }^{5}$ Os efeitos da doença no corpo e os eventos que ocorrem na vida das pessoas decorrentes do adoecimento são marcas constantes na vida delas e transformam seus cotidianos.

O corpo, além de ser objeto físico é o agente criativo das experiências e representa significados e valores diferentes para quem vive. Quando as pessoas passam por essa experiência há a singularização e o desprendimento da condição de vida que antecedia à doença. ${ }^{6}$

O momento da descoberta da enfermidade faz surgir incertezas, sofrimentos e ressignificações sobre o corpo na nova condição de saúde, que resulta em ações de enfrentamento da mesma por meio da busca ou não por atendimento nos serviços de saúde. ${ }^{8}$ Nesse sentido, é essencial produzir conhecimento das experiências e seus significados na vida das pessoas que visam a contribuir no reconhecimento da imperiosa necessidade de pautar as ações de saúde na singularidade de cada indivíduo e interferir no processo de adoecimento que pode vir a causar impacto no controle da doença.

Nessa perspectiva questiona-se que significados as pessoas com tuberculose atribuem às suas experiências de adoecimento? No intuito de responder esta questão o presente estudo objetivou compreender os significados das experiências corporais de pessoas em tratamento para tuberculose pulmonar.

\section{MÉTODO}

Trata-se de um estudo qualitativo que se utilizou do referencial teórico da antropologia em saúde para 
compreender o significado das experiências corporais no adoecimento das pessoas. ${ }^{5}$ Este referencial alicerçou-se teoricamente na compreensão de tais experiências de pessoas em tratamento para a tuberculose.

A experiência do adoecimento é produzida a partir do corpo, gerando multiplicidade de significados na descoberta, no tratamento e na cura. Dessa forma, compreende-se o corpo como um fenômeno global, onde representa a base da experiência e da intencionalidade em um determinado contexto. ${ }^{7-9}$

O estudo foi realizado com dez pessoas em tratamento para tuberculose pulmonar de um Programa de Controle de Tuberculose, da cidade de Pelotas-RS, no Sul do Brasil. O Programa é considerado referência em assistência no tratamento para a doença, tanto para a cidade como para os 22 municípios vizinhos e realiza o acompanhamento da pessoa e de seus familiares até a cura da doença.

Para a identificação e seleção dos participantes do estudo realizou-se uma busca de informações no prontuário e na ficha do Sistema Nacional de Notificação de Agravos (SINAN). Os critérios de seleção foram: estar na segunda fase de tratamento para a tuberculose (quatro meses finais que corresponde ao tratamento farmacológico padrão com duração de seis meses) e ter idade superior a 18 anos. Não foram incluídas pessoas com tuberculose extrapulmonar, hospitalizadas e aquelas privadas de liberdade. $\mathrm{O}$ critério de inclusão em relação ao período de tratamento deve-se ao entendimento que a partir desse período os sujeitos têm maior experiência sobre o seu adoecimento.

Após o levantamento de informações para identificação e seleção dos participantes do estudo foi realizado o contato telefônico com cada um deles, para saber sobre o interesse em participar do estudo, e, diante da vontade de participar, agendou-se o encontro, conforme disponibilidade da pessoa em relação ao dia, horário e local para a entrevista.

A coleta de dados foi realizada nos domicílios, por meio de entrevistas semiestruturadas, com tempo médio de duração de 40 minutos, entre abril e maio de 2015, guiada pelas seguintes questões: como foi ficar doente de tuberculose? Fale sobre o seu tratamento para a tuberculose? Fale sobre a sua família, desde quando você ficou doente? Como se sentiu no serviço de saúde?

O número de participantes não foi predeterminado, uma vez que era necessário obter os conteúdos que permitissem o alcance do objetivo do estudo. Dessa forma, optou-se pela finalização das entrevistas quando identificada a repetição dos discursos. Este processo fundamenta-se na compre- ensão de que em estudos qualitativos o pesquisador preocupa-se mais com o aprofundamento, a abrangência e adversidade no processo de compreensão do grupo a ser investigado. ${ }^{10}$

Antes da coleta de dados realizou-se um estudo piloto com cinco pessoas que não foram incluídas na análise dos dados. Desta forma o roteiro de entrevista foi validado em termos de entendimento das questões norteadoras do estudo.

Os dados foram analisados a partir do processo de análise temática de conteúdo, que contempla a fase de pré-análise, exploração do material e tratamento dos resultados. ${ }^{11} \mathrm{Na}$ primeira fase constituíram-se o corpus do estudo, que correspondeu as 10 entrevistas, organizadas segundo um quadro analítico para o agrupamento das mesmas, compondo-se de colunas distribuídas à esquerda para a ordem numérica de 1 a 10 e à direita aos nomes fictícios dos participantes e com material originário das falas. Desta forma foi preservado o anonimato dos participantes.

$\mathrm{Na}$ fase de exploração do material foram realizadas as leituras exaustivas das entrevistas e determinaram-se as unidades de registro, ou seja, palavras, frases ou parágrafos relacionados ao conteúdo e contexto (tuberculose, corpo, experiência, mudanças, estigma) e as duas categorias analíticas que nortearam a terceira etapa do estudo. A última etapa de tratamento dos resultados corresponde à interpretação dos dados, neste estudo resultou em duas categorias temáticas: o corpo sinalizador da doença e o corpo doente.

A pesquisa foi aprovada pelo Comitê de Ética em Pesquisa da Faculdade de Medicina da Universidade Federal de Pelotas (968.466/2015) conforme a Resolução n. 466/2012, conduzida de acordo com os padrões éticos exigidos. Os participantes assinaram o Termo de Consentimento Livre Esclarecido e também tiveram seu anonimato mantido, sendo identificados por nomes fictícios.

\section{RESULTADOS}

Os achados, neste estudo, apontam que os participantes manifestaram uma gama de significados atribuídos as experiências de adoecimento, e que o corpo doente sinalizou diversos sintomas, assim como a quebra das relações sociais e afastamento. As categorias trazem à tona a repercussão de um corpo que sofre pela presença da doença e também pelas mudanças impostas pela tuberculose advindas de um longo tratamento, que produz novos significados ao corpo. 


\section{O corpo sinalizador da doença}

Para os participantes o corpo sinalizador da doença refere-se à presença da tosse, dor nas costas, vômitos, emagrecimento, febre, cansaço e falta de ar, sinais estes que causaram transformações físicas, emocionais e sociais na vida das pessoas e de seu entorno familiar. Para eles, o corpo sinalizador significou que algo estava errado no próprio corpo, alterando a rotina da vida diária de trabalho, das relações, dos afetos, do lazer, dos hábitos alimentares, sono e locomoção.

Segundo Claudia, o corpo sinalizador da doença a impediu de trabalhar e continuar sua vida que levava até então, o estado de fraqueza e a dor nas pernas a dificultaram para caminhar. O corpo adquiriu um significado de esgotamento absoluto em razão de não suportar sua condição física atual. [...] é a segunda vez, comecei com muita tosse, tosse, tosse. Aí eu fui começando a emagrecer, emagrecer, mas eu sempre fui magra, nunca cheguei a $50 \mathrm{~kg}$, mas agora eu estava com $40 \mathrm{~kg}$, imagina. Eu estava me sentindo fraca, com as pernas fracas, caminhava e me dava uma dor nas pernas, aquele cansaço e eu não tinha força para caminhar. Imediatamente eu parei de trabalhar e já não suportava mais (Claudia).

Já para Marco e Maia, as alterações de sono sinalizaram mudanças no corpo. Marco revela sua dificuldade em dormir, decorrente da sudorese e escarro excessivo. Maia revela outros sinais que afetaram seu sono, além do relatado por Marco: "dor nas costas", "fincões nos pulmões" "vômitos", "dor de cabeça". Eu estava com 70 kg, eu não dormia à noite e quando dormia passava mal, me acordava suando e tinha que tirar toda a roupa e em questão de segundos já me dava frio e eu tinha de colocar tudo de novo. Então, não foi nada bom, foi muito ruim essa experiência. O problema do escarro, eu estava escarrando muito mesmo (Marco).

Os sintomas são horríveis. Tu não consegue dormir à noite, é dor insuportável, na frente, nas costas e em tudo. Tinha dias que eu não conseguia dormir, me dava uns fincões nos pulmões, no pulmão direito e eu passava a noite inteira gemendo de dor. Eu vomitava tudo o que eu comia. Tinha vezes que cada vez que eu ia comer eu pensava será que eu como ou será que eu não como, se eu não comer eu vou me desidratar e se eu comer vou vomitar. É horrível a dor de cabeça, a tosse que não pára nunca. Eu tinha suor noturno, eu chegava do serviço louca de frio, todo mundo num calorão e eu me tapava com dois cobertores dobrados em dois e trocava de blusa três vezes na madrugada. Eé horrível o sintoma, é horrível (Maia).

Mateus relata a presença de um corpo sinalizador da doença marcado pela falta de ar, febre e cansaço excessivo, o qual alterou a sua alimentação e locomoção. Estas manifestações o impediram de realizar atividades simples como comer e andar. $E u$ emagreci bastante, estava com $67 \mathrm{~kg}$ e o meu peso era 94 $\mathrm{kg}$. Senti uma falta de ar do caramba. Aumentou a dor no peito, a dor continuou. [...] eu passei muito mal, eu tinha muita febre, eu me sentia muito ruim. [...] eu tossia muito, muita dor nas costas, eu não comia, lá no serviço a gente tem horário de café, não comia nada, sempre estava cansado, ficava me arrastando. [...] febre todo o santo dia, eu tinha um cansaço que eu não conseguia nem caminhar daqui a frente assim, parece que eu estava morrendo e muita fraqueza, então, eu não recomendo para ninguém. É horrivel (Mateus).

Diferentemente dos outros entrevistados, para Julia, o corpo sinalizador, segundo sua experiência, não a alertou para a tuberculose. Ela possivelmente associou que a gripe desencadeou a tuberculose. Começou foi com uma gripe e eu até nem muita bola dei, aí passou a gripe e a tosse ficou, eu não sabia o que era. Eu estava me tratando como se fosse uma infecção que surgiu no pulmão, e que nada fosse tuberculose (Julia).

Maia reconheceu a doença, no entanto, ela não quis acreditar na possibilidade de estar com a tuberculose. Seu corpo sinalizador da doença significou a negação de ter a tuberculose. E todo mundo dizia assim, é uma gripe mal curada ou era uma pneumonia, mas todos os sintomas apontavam para a tuberculose $e$ dizem que o pior cego é aquele que não quer ver e eu não queria acreditar que fosse (Maia).

O corpo sinalizador da doença revelou-se na presença de sintomas (febre, emagrecimento, fraque$\mathrm{za})$, com isso as pessoas perceberam estes sintomas como sinais de alerta ou identificara-os como algo errado, que até então elas não haviam sentido em seus corpos. A partir disso desvelaram-se transformações pessoais, sociais e econômicas; sentir o impacto das alterações físicas provocadas pelos sintomas da tuberculose modificou as atividades cotidianas, aquelas essenciais para uma vida digna e à manutenção do bem-estar, como andar, conseguir se alimentar, ter um padrão de sono de qualidade, poder se relacionar com a família e o entorno social, assim como dar e receber amor por meio dessas relações e fez romper o vínculo com o trabalho.

\section{O corpo doente}

Para os participantes do estudo, o corpo doente significava que ter a tuberculose, é ser reconhecido como alguém que representa um risco para a saúde dos outros, afastamento dos familiares e amigos e mudanças sutis na relação com a família, 
no que diz respeito às atividades cotidianas traduzidas, principalmente pela separação de utensílios domésticos, simbólica e cotidianamente compartilhados por todos.

A separação de objetos (utensílios domésticos) é ainda presente no imaginário de muitas pessoas. Os participantes atribuem significados de forma ambivalente ao ato de separar tais objetos, pois, ao mesmo tempo em que essa atitude indica cuidado com o outro, também promove o estigma, como expressão a falta de aceitação social plena como mostra o depoimento de Paula e Jeremias: teve aquela função de dividir as coisas, porque eu estava doente e eu dividia tudo da cozinha, prato, copos, talheres. Tenho todas as minhas coisas separadas até agora, porque é um risco né, pode pegar. Tenho um filho pequeno e posso passar a doença para ele. Por isso preferi separar a louça (Paula).

A minha família ficou apavorada que eu peguei essa doença e separaram os talheres e essas coisas para não se contagiar. A minha mulher pegava e lavava bem os talheres, tudo separado e ela nunca pegou (Jeremias).

Na opinião de Laureano, ao realizar seu tratamento de diálise em outro serviço de saúde, o corpo doente significou o sofrimento pela ruptura das relações com a equipe de saúde, falta de interação, diálogo e afastamento dos profissionais da unidade. Laureano revela ainda a abordagem profissional inadequada de atenção às pessoas com tuberculose: os profissionais são mal informados sobre a doença, não sabem nada de tuberculose. A maioria das pessoas que me trataram como tuberculoses não sabem nada de tuberculose, principalmente aqui no hospital [Unidade de Hemodiálise] pelo desrespeito e pela desorganização. Aqui para falar contigo é uma briga, quando descobriram que eu tinha tuberculose nem chegavam para falar, ninguém te ligava, era uma briga para te ligar, uma discussão toda, todos os dias. [...] elas são mal informadas sobre o que é tuberculose. [...] Três anos depois, no lugar de aumentar o nível no hospital, o hospital voltou há décadas. [...] dentro do hospital eles ainda tratam como bicho de sete cabeças, eles não sabem o significado da doença (Laureano).

Segundo alguns participantes o corpo doente significou algo indesejável aos olhos dos próprios familiares, que levou as pessoas à exclusão de suas relações sociais. O significado de isolamento e sentimentos de exclusão para Julia despertou a mágoa e depressão. O corpo doente impõe para a vida dela segregação física e quebra de afetuosidade. Meu compadre antes da minha doença frequentava a nossa casa. Depois que descobriu que eu estava com tuberculose não deixava nem os filhos dele vir aqui e quando vinham chegavam na porta e ficavam três metros longe de mim, isso magoa e eu cheguei até ficar deprimida com isso (Julia).
O significado de afastamento dos familiares repercutiu no estado emocional de Maia, sentiu-se descontente pela presença do estigma da doença na família, que gerou distanciamento das pessoas mais próximas (sobrinhos) e outras mais distantes do núcleo familiar. Ainda, lamenta o fato de ter se afastado do trabalho. Contudo, Maia lidou com as atitudes de afastamento dos familiares de forma positiva passando a compreendê-las, uma vez que tais atitudes estavam imbricadas na proteção dos familiares e no medo do contágio. De vez em quando eu ficava chateada porque eu gosto de criança e minha irmã mandava as crianças irem para outra peça lá em casa. Todo mundo não chegava perto de mim porque eu estou doente. [...] tem um tio meu que se afastou que ele vinha seguido ver a minha avó e depois não veio mais. De início eu ficava chateada, depois não dei bola, não preciso dele mesmo. [...] quando as pessoas se afastaram, depois eu fui entendendo (Maia).

Conforme Claudia, o corpo doente pela tuberculose significou o autoisolamento, ou seja, esse ato foi voluntário. Esta atitude justificou-se pela preocupação de transmitir a tuberculose para os familiares, pois ela evitou ficar próxima aos seus filhos: eu mesma procurava sempre ficar até mais sozinha, no primeiro mês que diz que é mais perigoso que logo a gente começa a tomar o remédio, eu cuidava muito para não pegar nos meus filhos (Claudia).

O corpo doente significou para os participantes a percepção de risco à saúde coletiva pelo medo de transmitir a doença aos familiares, amigos e comunidade, o afastamento das relações sociais, visto que muitos familiares ao descobrirem o diagnóstico de tuberculose passaram a isolar o doente, não mantendo nenhum contato no período de tratamento, e isso gerou rompimento nas relações intrafamiliares como conviver com sobrinhos e tios, potencializando a presença do estigma na sociedade. O isolamento também foi desvelado pela ação de separar os utensílios domésticos (copos, talheres, camas), no qual as pessoas foram forçadas a comer e a dormir separadamente dos demais membros. Além disso, o autoisolamento foi manifestado como forma de proteção aos filhos, com o propósito de evitar a transmissão da doença nos primeiros dias de tratamento.

Os resultados, apresentados em suas duas categorias, evocam o sentido de vivenciar a tuberculose: a doença que pressupõe a condenação da vida, impõe a limitação da vida, física e social, imposta por ela e por seu tratamento. A vivência foi sofrida e limitante. O sentido de vivenciar o adoecer de tuberculose foi manifestado por meio 
do corpo sinalizador, caracterizado por sintomas que alteraram o cotidiano de vida das pessoas e as mais simples atividades da vida, de trabalho, estudo e lazer. O corpo doente traduziu-se no medo de contágio da tuberculose, no afastamento social, nas mudanças de relações, na permanência do estigma, na separação de utensílios, no isolamento e autoisolamento. Isso fez romper vínculos e transformar a vida de todos os envolvidos, sobretudo daqueles que sofreram pela doença.

\section{DISCUSSÃO}

O corpo é agente físico e subjetivo da experiência, a partir do qual se produzem os significados e as ações, portanto, ele é fonte criativa da experiência de vida, da saúde e do adoecimento. ${ }^{7-9}$ No presente estudo o corpo com tuberculose produziu diversos significados, os quais se modificam no decorrer do tempo e ao longo tratamento, se inicialmente as pessoas vivenciaram o período de limitações, tanto físicas quanto emocionais, logo sentiram mudanças positivas pelo tratamento, criaram estratégias efetivas para superar os momentos difíceis e vislumbram um recomeço de vida.

O primeiro significado do corpo com tuberculose é relatado pelos participantes do estudo como o sofrimento físico pela presença dos sintomas conforme identificado também em outros estudos. ${ }^{12-13}$ Estes sintomas são frequentes em um corpo que sinaliza que algo está organicamente em descompasso e não menos importante revela os sentimentos, sensações e emoções florescentes de uma nova realidade: ter e viver com a tuberculose.

Desta forma, compreende-se que a doença é experimentada através do corpo, contudo, este não é simplesmente um objeto físico ou estado fisiológico, senão parte essencial do eu. ${ }^{9}$ Assim, o corpo (objeto físico) não pode ser nitidamente diferenciado dos estados de consciência.

Embora os significados sejam construídos a partir do dia a dia, das experiências prévias e das vivências de cada um, o corpo sinalizador manifestou-se a partir da construção de uma realidade comum a esse grupo social..$^{7-9}$ Esta realidade refere-se às pessoas que tiveram como primazia de significado do corpo sinalizador os sintomas tosse, dor nas costas, vômitos, emagrecimento, febre, cansaço, falta de ar, assim, sinalizando algo de errado e interrompendo as atividades diárias de vida.

As pessoas sentem vergonha por ter tuberculose e associam a doença como algo ruim e perturbador, com a atribuição da expressão doença suja. ${ }^{14}$
Tais significados carregados de uma conotação desagradável estão presentes neste estudo, quando os participantes Maia e Mateus revelam que seus familiares se afastaram após descobrir a doença ou separaram talhares, percebe-se, então, a permanência da mistificação da tuberculose e o preconceito associado a ela.

Neste caso, há uma distinção popular entre o mundo da realidade objetiva e o da experiência subjetiva o que acaba refletindo no corpo social e político. ${ }^{9}$ Isso significa que as experiências corporais além dos significados intersubjetivos refletem experiências de adoecimento e práticas sociais que canalizam o comportamento de estar e se sentir doente.

Pesquisa cujo objetivo foi compreender o compromisso do enfermeiro no cuidado à pessoa com tuberculose demonstrou que este profissional é capaz de ajudar a pessoa a libertar-se do medo da doença, rompendo preconceitos e estigmas. Assim, é essencial que todos os profissionais assumam o compromisso de ajudar a pessoa a se recuperar de uma forma menos sofrida e, sobretudo, influenciar a família para encorajá-la no enfrentamento do adoecimento. ${ }^{15}$

O significado do corpo doente resulta em isolamento social permanente, pois as pessoas deixaram de manter o convívio com o entorno social, justamente por estarem doentes. Julia passou por esta experiência ao revelar e sentir-se isolada diante da rejeição e afastamento sofridos por parte do tio, que após descobrir a doença da sobrinha, mudou o seu comportamento e se apartou dela.

O corpo doente significou o convívio com uma nova identidade, que passa a ser deteriorada por aspectos de preconceito e isolamento socialmente construídos e perpetuados no imaginário das pessoas. Esta identidade que surge é em razão da tuberculose e sua multidimensão física, emocional, social e histórica, permeada por um modo particular de ser no mundo, baseado em experiências prévias e em influências do meio social.

Os achados colaboraram com outros estudos ao apontarem isolamento, autoisolamento, estigma e afastamento do convívio social das pessoas com tuberculose. ${ }^{16-18}$ A experiência do corpo doente para Maia foi fortemente imbuída de sinais de afastamento por parte de seus familiares, assim, revelase um contexto caracterizado por distanciamento da família contrário à atitude de apoio necessário para o enfrentamento da doença, caracterizando a presença do estigma.

Enfatiza-se a preocupação de enfermeiras para superar a presença do estigma, preconceito e rejeição 
ainda existentes em muitos contextos, tanto dentro das famílias, entre os amigos, como no trabalho das pessoas com tuberculose. Isso se configurou em ações e esforços para ajudar as pessoas a perceberem que eram conceitos sem fundamento. ${ }^{15}$

Ainda, destacam-se os esforços das enfermeiras para não isolar a pessoa com a doença ou fazê-la se sentir inferior por estar com uma doença transmissível. ${ }^{15}$ Sendo assim, vários participantes deste estudo, se tivessem recebido orientações e apoio por parte dos profissionais, como orientações à pessoa e sua família do que, de fato, deveria ser feito dentro de casa, afastando mitos como isolar totalmente a pessoa acometida, o desfecho de muitas angústias e medos teria se transformado em momentos de mais tranquilidade.

Identificou-se a multiplicidade de sentimentos que permeia o percurso de vida das pessoas com tuberculose. ${ }^{18-22}$ As emoções e sentimentos citados em estudos são: choque, autodescriminação, medo do risco de infecção, choro, dúvidas sobre o diagnóstico e tratamento, sentimento de vergonha e ainda a necessidade de manter em segredo a condição de ter a doença. ${ }^{14-18} \mathrm{Na}$ presente investigação, a perturbação, o isolamento, a rejeição e a tristeza, foram os sentimentos e emoções reveladas por Paula, Julia, Maia e Laureano.

Estudo sobre a qualidade de vida mostrou mudanças produzidas na vida das pessoas com tuberculose, metade das pessoas informaram que a doença afetou os movimentos para caminhar longas distâncias e o comprometimento da saúde para as atividades diárias e de trabalho. ${ }^{23}$ Este aspecto também foi identificado nas falas de Claudia e Mateus, em suas experiências do corpo sinalizador da doença, que mencionaram as dificuldades cotidianas para caminhar, impossibilitando simples tarefas diárias.

Outro estudo revelou o impacto físico da tuberculose nas experiências corporais, que dificultou a adesão ao tratamento farmacológico pela presença dos sintomas debilitantes. ${ }^{16}$ Estes sintomas físicos também foram relatados por Mateus e Maia no presente estudo.

Estudo realizado em país desenvolvido, onde a tuberculose não representa uma ameaça para a saúde pública, revelou que pessoas com a doença solicitaram demissão do local de trabalho para não haver a investigação da presença da tuberculose entre os colegas. ${ }^{24} \mathrm{Na}$ experiência de Cláudia a presença da doença significou autoisolamento, principalmente pela preocupação em transmitir a doença às outras pessoas. Dessa forma, identifica-se que a realidade comum associada à doença é o medo, a vergonha e a constante preocupação e cuidado para não transmitir a doença.

Estudo com profissionais e estudantes que adoeceram por tuberculose mostrou a presença de estigma, autosegregação (tradução da palavra: selfsegregation), além de mecanismos de defesa, como a negação, isolamento e a ocultação da doença. ${ }^{16} \mathrm{O}$ corpo doente significa viver e conviver com a doença, lidando de forma contínua e variável com esse mundo desconhecido de ter a tuberculose.

Para as pessoas que vivenciam a tuberculose há o aparecimento de diversos sentimentos e consequências do adoecer, esse processo é multifacetado. A doença por vez é oculta, é discriminante. Pode ser tocável em qualquer status quo, contudo cada pessoa sentirá de uma maneira o seu adoecimento e tecerá uma gama de significados.

\section{CONCLUSÃO}

A análise e interpretação dos dados do estudo apontaram duas categorias temáticas: o corpo sinalizador da doença e o corpo doente revelando a repercussão da tuberculose na vida das pessoas e familiares, tais como: transformação no convívio familiar, social e de trabalho, medo, rejeição e insegurança.

As pessoas mencionaram o corpo doente como experiência viva e em transformação, atribuindo significados a ele no sentido de readaptação diária a nova condição de vida, as escolhas e decisões. Os significados também permitiram identificar a forma como as pessoas são percebidas na sociedade, antes e após a presença da doença.

As experiências corporais foram fortemente influenciadas pela subjetividade das pessoas (experiências prévias, vivenciadas e socializadas pelo senso comum, além do universo particular de crenças, valores e aspectos culturais). Portanto, devem ser entendidas como questão que transcende o aspecto meramente biológico.

Não há dúvida de que os significados atribuídos ao corpo na presença da doença poderão influenciar no autocuidado e na coparticipação da pessoa para o diagnóstico e tratamento da tuberculose. Sentimentos de medo e vergonha, assim como o estigma e preconceito que ainda se fazem presentes no imaginário das pessoas, podem resultar em demora na busca por serviços de saúde para o diagnóstico da doença.

Embora as experiências corporais resultantes da condição de ter tuberculose apontem as alterações físicas do corpo pela doença, os significados dos 
participantes extrapolam essas experiências. Eles produzem sentidos na dimensão social e afetiva. Há experiências em todas suas modalidades sensitivas, que é decorrente do ouvir aos outros, de olhar o afastamento das pessoas e da impossibilidade do toque.

O estudo apontou como limitação metodológica a subjetividade do investigador, o que implica no risco de perder a objetivação e acaba influenciando na ánalise e interpretação dos depoimentos. Ainda, a compreensão do outro e de sua realidade pode sofrer uma redução a algo que envolva a introspecção do próprio pesquisador, baseada na sua familiaridade, estranhamento, algo dito, feito, celebrado ou cristalizado.

Sugere-se para futuras pesquisas a valorização da interface pessoa (doente) e serviço de saúde (profissionais) para que se possa identificar uma realidade na qual seriam conhecidas as necessidades do contexto do serviço de saúde e também a dimensão particular de pessoas. Desta forma, será possível pensar em mudar e/ou superar o preconceito e o distanciamento que ainda permeia o processo assistir nos serviços de saúde.

\section{Agradecimentos}

Às pessoas que vivenciaram a tuberculose e tiveram suas vidas transformadas pela doença e que, mesmo diante deste momento de rupturas, se dispuseram em compartilhar as suas experiências de adoecimento, possibilitando a construção desta pesquisa. À FAPERGS pela contribuição dos recursos financeiros para a elaboração da pesquisa.

\section{REFERÊNCIAS}

1. World Health Organization (WHO). Global tuberculosis report 2013: WHO report 2013 [internet]. Geneva (CH): 2016 [cited 2016 Apr 08]. Available from: apps.who.int/ iris/bitstream/10665/91355/1/9789241564656_eng.pdf

2. Piller RVB. Epidemiologia da tuberculose. Pulmão RJ [internet]. 2012 [cited 2016 Apr 07]; 21(1):4-9. Available from: sopterj.com. br/profissionais/_ revista/2012/n_01/02.pdf

3. Barreto ML, Teixeira MG, Bastos FI, Ximenes RAA, Barata RB, Rodrigues LC, et al. Sucessos e fracassos no controle de doenças infecciosas no Brasil: o contexto social e ambiental, políticas, intervenções e necessidades de pesquisa. Lancet [internet]. 2011 [cited 2016 Mar 07]; 6(3):47-60. Available from: http:/ / bvsms.saude.gov.br/bvs/artigos/artigo_saude_ brasil_3.pdf

4. Charmaz K. From the "sick role" to stories of the self: understanding the self in illness. In: Ashmore RD, Contrada RA. Self and identity: interdisciplinary explorations in physical health. New York (NY): Oxford University Press; 1999.

5. Conrad P. The experience of illness: recent and news directions. In: Roth JA, Conrad P. Research in the Sociology of Health Care. Connecticut (CT): JAI Press; 1987.

6. Gadamer HG. O mistério da saúde: o cuidado da saúde e a arte da medicina. Porto (PT): Edições 70; 2002.

7. Good BJ. Medicina, racionalidad y experiencia: una experiencia antropológica. Barcelona (ES): Edición Bellaterra; 2003.

8. Dodor EA. The feelings and experiences of patients with tuberculosis in the Sekondi-Takoradi metropolitan district: implications for TB control efforts. Ghana Med J [internet]. 2012 [cited 2016 Mar 15]; 46(4):211-8. Available from: http://www.ncbi. nlm.nih.gov/pubmed/23661839

9. Good BJ. Medicine, rationality and experience: an anthropological perspective. Cambridge (ENG): Cambridge University Press; 1994.

10. Deslauriers JP, Keriset M. O delineamento de pesquisa qualitativa. In: Poupart JA. Pesquisa qualitativa: enfoques epistemológicos e metodológicos. Rio de Janeiro (RJ): Vozes; 2008.

11. Bardin L. Análise de conteúdo. São Paulo (SP): Edições 70; 2011.

12. Cirino AC, Juskevicius LF, Alves H, Silva WV. Aspectos emocionais vivenciados por pacientes portadores de tuberculose. Rev Paul Enfermagem [internet]. 2009 [cited 2016 Apr 01]; 28(2):50-5. Available from: http://bases.bireme.br/cgi-bin/ wxislind.exe/iah/online/?IsisScript=iah/iah.xis\&s $\mathrm{rc}=$ google\&base $=$ LILACS\&lang $=\mathrm{p} \&$ nextAction $=\operatorname{lnk}$ \&exprSearch $=755295 \&$ indexSearch $=$ ID

13. Silva JB, Cardoso GCP, Netto AR, Kritski AL. Os significados da comorbidade para os pacientes vivendo com TB/HIV: repercussões no tratamento. Physis [internet]. 2015 [cited 2016 Mar 11]; 25(1):20929. Available from: www.scielo.br/pdf/physis/ v25n1/0103-7331-physis-25-01-00209.pdf

14. Juniarti N, Evans DA. Qualitative review: the stigma of tuberculosis. J Clin Nurs [internet]. 2011 [cited 2016 Mar 22]; 20(13-14):1961-70. Available from: http:/ / www.ncbi.nlm.nih.gov/pubmed/21040040

15. Cavalcante, EFO, Silva, DMGV. O compromisso do enfermeiro com o cuidado à pessoa com tuberculose. Texto Contexto Enferm [internet]. 2016 [cited 2016 May 26]; 25(3):5-10. Avaiable from: http://dx.doi. org/10.1590/0104-07072016003930015.

16. Andrade EDT, Hennington ÉA, Siqueira HRD, Rolla VC, Mannarino C. Perspectives of Patients, Doctors and Medical Students at a Public University Hospital in Rio de Janeiro Regarding Tuberculosis and Therapeutic Adherence. PLoS One [internet]. 2015 [cited 2016 Feb 25]; 10(9):1-17. Available from: http:/ / journals.plos.org / plosone / article?id=10.1371/ journal.pone.013757 
17. Mohammed S, Nagla S, Morten S, Asma E, Arja A. Illness perceptions and quality of life among tuberculosis patients in Gezira, Sudan. Afr Health Sci [internet]. 2015 [cited 2016 Abr 07]; 15(2):385-93. Available from: http://www.ncbi.nlm.nih.gov/ pubmed/26124783

18. Dodor EA. The feelings and experiences of patients with tuberculosis in the Sekondi-Takoradi metropolitan district: implications for control efforts. Ghana Med J [internet]. 2012 [cited 2016 Mar 15]; 46(4):211-8. Available from: http://www.ncbi.nlm. nih.gov/pubmed/23661839

19. Basu G, Chatterjee C, Singh R, Biswas S. Prevalence of depression in tuberculosis patients: an experience from a DOTS clinic. IJRRMS [internet]. 2012 [cited 2016 Mar 15]; 2(4):1-4. Available from: http:/ / www.ijrrms. com/pdf/2012/oct-dec-12-pdf/04.pdf

20. Nunes TTS. A tuberculose em Kafka: corpo, escrita, vida e morte. Pulmão RJ [internet]. 2007 [cited 2016 Mar 26]; 16(2-4):111-13. Available from: sopterj.com. br/profissionais/_revista/2007/n_02-04/12.pdf
21. Duarte LFD, Leal OF. Doença, sofrimento, perturbação: perspectivas etnográficas. Rio de Janeiro (RJ): FIOCRUZ; 1998.

22. Baral SC, Karki DK, Newell JN. Causes of stigma and discrimination associated with tuberculosis in Nepal: a qualitative study. BMC Public Health [internet]. 2007 [cited 2016 Mar 27]; 16(7):211. Available from: http:/ / www.ncbi.nlm.nih.gov/pubmed/17705841

23. Farias SNP, Medeiros CRS, Paz EPA, Lobo AJS, Helman LGG. Integralidade no cuidado: estudo da qualidade de vida dos usuários com tuberculose. Esc Anna Nery [Internet]. 2013 [cited 2017 Dec 22]; 17(4):749-54. Available from: http:/ / www.scielo.br/ pdf/ean/v17n4/1414-8145-ean-17-04-0749.pdf

24. Faccini M, Cantoni S, Ciconali G, Filipponi MT, Mainardi G, Marino AF, et al. Tuberculosis-related stigma leading to an incomplete contact investigation in a low-incidence country. Epidemiol Infect [internet]. 2015 [cited 2016 Mar 22]; 143(13):2841-8. Available from: http://www.ncbi.nlm.nih.gov/ pubmed/25600903
Correspondência: Bianca Contreira de Jung Fundação Universitária do Rio Grande - Escola de Enfermagem General Osório s/nº Campus da Saúde 96201-900 - Rio Grande, RS, Brasil E-mail: biancajung@furg.com.br
Recebido: 28 de março de 2016 Aprovado: 27 de julho de 2017

This is an Open Access article distributed under the terms of the Creative Commons (CC BY). 